\title{
социоЛОГИЯ
}

DOI: $10.17805 /$ ggz.2019.2.6

\section{Коррупция в свете социологических теорий}

\author{
А. Н. Пинчук
}

Институт социально-политических исследований РАН, г. Москва

В статье феномен коррупиии анализируется в рамках различных соииологических теорий, позволяющих его рассмотреть в качестве девиантного поведения, особой разновидности сочиальных практик и сочиального концепта. Автор раскрывает тематику коррупции параллельно развитию сочиологической мысли, актуализируя познавательный потенциал классических работ в теориях современных исследователей. Представленные теоретические подходы объединяются единой линией сочиологического анализа, демонстрирующей сложную и тесную связь субъекта коррупиионных действий и социокультурных условий жизни общества. Особое внимание уделяется конструированию девиантности коррупции в общественном дискурсе, показываются перспективы исследования коррупиии как сочииального конųenma.

Ключевые слова: коррупция; девиантное поведение; коррупционные практики; конструирование девиантности; социальный концепт

\section{Corruption in the Light of Sociological Theories}

\author{
A. N. Pinchuk \\ Institute of Socio-Political Research, \\ Russian Academy of Sciences, Moscow
}

The article analyzes the phenomenon of corruption in the framework of sociological theories that give us an opportunity to consider it as deviant behavior, a special kind of social practices and social concept. The author discusses the theme of corruption, in parallel with the development of sociological thought, actualizing the heuristic potential of classical works in theories proposed by modern researchers. The theoretical approaches demonstrate a close relationship between the subject of corruption and socio-cultural conditions of society. A special attention is paid to constructing the deviant nature of corruption in the public discourse. The prospects for the study of corruption as a social concept are shown. 
Keywords: corruption; deviant behavior; corruption practices; construction of deviance; social concept

\section{ВВЕДЕНИЕ}

В современном социально-гуманитарном знании оформилась традиция исследовать коррупцию как самостоятельный социальный феномен, который приобретает двоякий контекст осмысления в качестве теоретической и практической проблематики. Как реальная общественная проблема, требующая своего практического решения, коррупция представляет особый предмет антикоррупционной политики. Концепцию государственной политики в сфере борьбы с коррупцией отражают нормативные документы, принятые в последнее время. Так, в Стратегии национальной безопасности страны феномен коррупции приобретает черты зримой угрозы государственным и общественным интересам, поэтому «особое внимание уделяется искоренению причин и условий, порождающих коррупцию, которая является препятствием устойчивому развитию Российской Федерации и реализации стратегических национальных приоритетов» (Указ Президента ... , 2015: Электронный ресурс).

Практику государственного регулирования антикоррупционной политики определяют задачи Национального плана противодействия коррупции, поэтапно принимаемого каждые два года (последний утвержден на 20182020 годы) (Указ Президента ..., 2018: Электронный ресурс). Примечательно, что в обозначенном документе помимо мер правоприменительного характера, отмечается тенденция к усилению «просветительских, образовательных и иных мероприятий, направленных на формирование антикоррупционного поведения государственных и муниципальных служащих, популяризацию в обществе антикоррупционных стандартов и развитие общественного правосознания» (там же).

Таким образом, в концептуальных основах стратегического планирования антикоррупционной политики проявляется понимание того, что борьба с коррупцией имеет социально-культурные предпосылки. Но достигнуто ли в полной мере понимание того, что коррупция обладает свойствами особого социального явления, опосредованного комплексом социальноэкономических, политических, социокультурных и иных противоречий? Исходя из текста программного документа, определяющего план борьбы с коррупцией до 2020 года, однозначный вывод сделать сложно, так как меры антикоррупционного просвещения представлены достаточно сжато, более того, обозначен «поиск форм и методов воздействия на различные слои населения в целях формирования негативного отношения к данному явлению» (там же). Тем не менее стремление применять меры социально-культурного характера символизирует об определенном сдвиге в государственных решениях. И, по- 
скольку задачи выдвинуты и закреплены, необходимо двигаться в направлении развития антикоррупционного просвещения, образования и, возможно, воспитания.

В этих ориентирах следует учитывать сложную и тесную связь субъекта коррупционных действий и социальной среды, так как воздействие исключительно через личностные детерминанты будет недостаточным. Как было замечено на 33-м конгрессе Немецкого общества социологов, распространение коррупции в первую очередь указывает на кризис общественных институтов, который проявляется не только в девиантном поведении отдельных индивидов, но и в неравномерном «распределении общественных ресурсов, таких, как деньги, власть, репутация, моральный авторитет» (Заурвайн, 2012: 107). Поэтому инициативные предложения по антикоррупционной деятельности нуждаются в социологической перспективе анализа. К такому выводу подталкивает и другое важное обстоятельство. Если исходить из того, что модель антикоррупционной политики представляет собой социальный проект, в котором затрагивается широкий круг исследовательских вопросов для оценки приемлемости предлагаемых мероприятий (Луков, 2006), то невнимание к социологическому знанию может повлиять на эффективность решений в социальном проектировании. Чтобы иметь ясное представление о реалистичности условий, в которых будет осуществлена антикоррупционная деятельность, потребуются концептуальная проработка причин возникновения и распространения коррупции в жизни индивида и общества. Это придает особую ценность теоретической работе, позволяющей осветить наиболее значимые концептуальные идеи социологии о сущности социального явления коррупции и причинах его возникновения, что и определило цель данной статьи.

\section{НАПРАВЛЕНИЯ СОЦИОЛОГИЧЕСКОГО АНАЛИЗА КОРРУПЦИИ}

Несмотря на столь длительную историю существования, коррупция как особый предмет социологического анализа имеет относительно непродолжительную традицию изучения ${ }^{1}$. Данная особенность отнюдь не сужает границы социологической рефлексии, а позволяет отметить тот факт, что коррупция редко находилась в центре специальных научных изысканий. Тем не менее фундаментальные разработки классиков социологической мысли откры-

\footnotetext{
${ }^{1}$ Следует уточнить, что научный задел в области изучения коррупции начинает приобретать конкретные черты только в конце 60-х годов прошлого века, что принято связывать с публикацией книги С. Алатаса «Социология коррупции» (Alatas, 1968). Хотя социологический анализ в этой работе практически не представлен, издание книги послужило дальнейшему развитию тематики коррупции в социологии.
} 
вают широкие просторы для теоретической интерпретации социальных аспектов коррупции. Отсюда следует, что концептуализация феномена коррупции начинает свое развитие с базовых социологических понятий и идей и продолжается в контексте теорий, которые хотя и развивались за рамками проблематики коррупции, однако приобрели теоретическую новизну в трудах современных авторов. Такое концептуальное выражение получили подходы к изучению коррупции, истоки которых оформились в теории аномии Э. Дюркгейма и Р. Мертона, «идеального типа» бюрократии М. Вебера, теории самореферентных систем Н. Лумана, в разработках П. Бурдье, М. Фуко и др.

Анализ теоретических идей в области коррупции может определяться следующими задачами. Во-первых, в социальном проектировании необходимо исходить из того, что коррупция представляет не абстрактное социальное явление, «зло» или «болезнь общества», а реальные действия преступного характера, совершаемые в конкретных социокультурных условиях (Карепова, Некрасов, Пинчук, 2018; Osipov et al., 2018). И если довольно часто декларируется мысль о том, что в обществе складывается особая обстановка и на поведение индивида оказывают влияние определенные социальные условия, то следует уточнить, в чем причина их появления и какие конкретно это условия.

Во-вторых, учитывая то, что в последнее время все большую значимость приобретает антикоррупционное просвещение, необходимо затронуть проблему неоднозначного понимания коррупции в обыденной жизни и вытекающие из этого вопросы об основаниях негласного оправдания некоторых коррупционных случаев. В данном контексте коррупция представляет интерес как социальный концепт, приобретающий определенное значение в повседневном дискурсе того или иного общества.

Таким образом, можно обозначить три направления теоретического анализа, которые позволяют рассмотреть коррупцию как девиантное поведение, латентные социальные практики и социальный концепт. В каждом из этих направлений могут объединяться несколько социологических теорий, выражающих различные точки зрения в едином фокусе анализа. Рассмотрим эти теории и попытаемся сформулировать общие выводы.

1. Коррупция как девиантное поведение. В широко распространенной трактовке коррупция определяется как особый вид отклоняющегося от социальной нормы поведения. В этом смысле привлекают внимание объяснительные модели Э. Дюркгейма, артикулирующие социальные аспекты противоправных действий (Дюркгейм, 1996, 2006).

Дюркгейм оперирует понятиями, отсылающими к представлению об обществе как об особом коллективном, надындивидуальном образовании. По 
Дюркгейму действие следует относить к преступным, если оно противоречит коллективным чувствам, нарушает определенное состояние коллективного разума (Дюркгейм, 1996). Однако не все противоправные поступки в равной мере возмущают коллективное сознание, и не ко всем применяется одинаковая интенсивность наказания: «Так, сговор чиновников, вторжение судебных властей в административные, религиозных функций - в гражданские представляют объект кары, непропорциональной вызываемому ими в сознаниях негодованию» (там же: 90).

На самом деле меру пресечения и наказания определяет правительственная власть, и серьезные санкции применяются прежде всего к тем преступлениям, которые угрожают ее авторитету и функционированию. Это происходит из-за того, что основная функция аппарата управления - защищать коллективное сознание. По словам Дюркгейма, власть является «символом общего сознания», это не просто социальная функция, а «коллективный тип» (там же: 92). И поскольку власть является воплощением силы, диффузно распространенной в обществе, постольку «она называет преступлениями поступки, которые ее возмущают, не возмущая, однако, в той же степени коллективные чувства» (там же: 93). При этом Дюркгейм приходит к парадоксальному, на первый взгляд, выводу — преступления не свидетельствуют о патологическом состоянии общества. Иначе это потребовало бы усиления реакции всех коллективных чувств, что привело бы к суровым наказаниям даже за малейшие проступки. Дюркгейм считает, что в какой-то мере терпимость к определенным правонарушениями необходима. С точки зрения французского ученого, пластичность нравственных чувств общества гарантирует социальные изменения (Дюркгейм, 2006: 86-90). Смысл данных рассуждений исходит из той идеи, что преступления имеют глубокие социальные корни и ликвидировать их полностью практически невозможно. Однако эти теоретические представления отнюдь не провозглашают тщетность правоприменительной деятельности. Напротив, по замыслу автора, они призваны обновить взгляды на практику наказания, так как «наказание и преступление составляют одну нераздельную пару» (Дюркгейм, 2018: 400).

Э. Дюркгейм считает, что если преступность прогрессирует и увеличивается, то это уже принимает патологический характер и с этим необходимо бороться. Чрезмерный рост преступлений в свою очередь свидетельствует о социальной аномии. Изначально аномия упоминается в работах Дюркгейма в рамках анализа анормальных форм разделения общественного труда, которые связаны с «нарушениями органической солидарности» (Дюркгейм, 1996: 361-403). Впоследствии Дюркгейм более подробно рассмотрит причины аномии при изучении аномичного вида самоубийства. Согласно заключению ученого, аномия проявляется в результате ослабления воздействия социума 
на индивида в период кризисов или, напротив, благоприятных, но резких социальных изменений, ведущих к социальной дезорганизации (Дюркгейм, 2018: 267). В описании автора, это такое состояние общества, когда «никто не знает в точности, что возможно и что невозможно, что справедливо и что несправедливо; нельзя указать границы между законными и чрезмерными требованиями и надеждами, а потому все считают себя вправе претендовать на все» (там же: 268). Здесь будет не в новинку утверждение о том, что провоцировать рост коррупции может дезорганизация общества и состояние неопределенности, когда традиционные нормы, потеряв свою значимость, не приобрели иного содержания, а люди, утратив прежние ориентиры, не нашли новые. Но данные теоретические построения важны для понимания недостаточности антикоррупционных мер, когда ослаблены социальные связи.

В дальнейшем идеи о социальной структуре и аномии будут переосмыслены Р. Мертоном, который рассмотрит причины возникновения девиантного поведения в контексте рассогласованности культурных целей и институционализированных практик их достижения (Мертон, 2006). Основное внимание ученый сосредоточит на экономической сфере и в качестве культурного образца рассмотрит богатство, символизирующее успех. Исходя из этого, Мертон выделит несколько типов реакций, среди которых инновационная форма приспособления реализуется через использование нелегитимных средств достижения цели (к ним можно отнести и коррупцию): «Эта реакция возникает, когда индивид усвоил культурное акцентирование цели, не интернализировав при этом в равной степени институциональные нормы, регулирующие пути и средства ее достижения» (там же: 257).

Аналогичным образом можно определить и коррупцию как инновационный тип девиантного поведения. Иными словами, это нелегальный способ получения желаемых благ, нарушающий институциональные правила, что в очередной раз показывает роль социокультурных условий. Здесь важно другое - как происходит формирование данных культурных образцов? Мертон делает ряд важных замечаний по этому поводу и указывает на то, что высокий уровень девиации обусловлен не только чрезмерным акцентированием значимости той или иной культурной цели как жизненной стратегии, но и особенностями социальной структуры, жесткие межклассовые границы которой могут сужать круг возможностей для достижения данной цели легитимным способом (там же: 264). Однако это не единственный источник, провоцирующий «предрасположение к аномии». Одну из ключевых ролей в формировании культурных амбиций, свойственных определенной социальной страте, также играет семья. Согласно Мертону, в ходе социализации индивид «деятельно вовлекается в поиск и усвоение неявных парадигм культурного оценивания, категоризации людей и вещей и иерархизации достойных ува- 
жения целей» (там же: 279). Процесс социализации слишком сложный и требует отдельного обсуждения, но вопрос о том, какие культурные амбиции осваиваются в российских семьях, сможет стать актуальным при изучении коррупции.

2. Коррупщия как социальные практики. Коррупция может быть рассмотрена как особый вид латентных социальных практик, воспроизводимых участниками коррупционных отношений. Этот тезис имеет за собой целую плеяду социологических теорий, оформившихся в рамках структуралистского конструктивизма (Н. Элиас, П. Бурдье, Э. Гидденс и др.).

Представители конструктивистских подходов исходили из возможности «деконструировать» социальный мир, пытаясь преодолеть разграничение микро- и макроуровней, коллективного-индивидуального, объективногосубъективного (Коркюф, 2002: 12). Как считал П. Бурдье, необходимо избегать «реализма структуры» и «не впасть в субъективизм», а для этого следует вернуться к практике - «...объективированным и инкорпорированным продуктам практической истории, структурам и габитусам» (Бурдье, 2001: 102). Именно понятия «габитус» и «диспозиции» становятся ключевыми для анализа коррупционных практик.

Следует заметить, что в авторском определении П. Бурдье габитус представляет «системы устойчивых и переносимых диспозиций, структурированные структуры, предрасположенные функционировать как структурирующие структуры, т. е. как принципы, порождающие и организующие практики и представления...» (там же: 103). Габитус отражает определенные схемы восприятия, мышления, оценивания мира, действий. Как система диспозиций, габитус актуализируется через практики. При этом сами практики опосредованы условиями, в которых они были изначально сформированы, но также соотносятся и с теми условиями, в которых непосредственно воспроизводятся (там же: 110).

По словам Л. Вакана, в теоретических построениях П. Бурдье, с одной стороны, затрагивается конструирование объективных структур (objective structures), которые создают внешние ограничения социальным взаимодействиям. С другой стороны, акцентируется жизненный опыт социальных субъектов при рассмотрении категорий восприятия и диспозиций, структурирующих действие изнутри. Тем самым подчеркивается определенная взаимосвязь между социальными и ментальными структурами (mental structures) (Wacquant, 1992: 11-12).

Дж. де Грааф использует разработки Бурдье в качестве опорной теоретической модели для исследования коррупции (Graaf, 2007). Ученый считает, что при изучении коррупционных практик важно учитывать наличие соответствующих диспозиций. Сами по себе диспозиции не являются прямыми 
стимулами к действию. Они представляют некий «спусковой механизм» (specific trigger) и отражают те социальные условия, в которых изначально оформились. Поэтому при изучении определенных коррупционных случаев следует учитывать категории восприятия, оценки и жизненного опыта коррупционеров, факты их биографии (личное дело), мотивы, ситуацию совершения коррупционных действий и благоприятствующие этому обстоятельства (там же: 72).

Эти выводы можно рассмотреть и в ином аспекте. Если напомнить, что в результате опривычивания определенных действий и их постоянного воспроизводства формируются социальные институты, то аналогичную параллель можно провести по отношению к распространению коррупционных практик. Стихийное освоение социальных практик и их распространение в формальных организациях в качестве типичных форм теневого взаимодействия между участниками коррупционных отношений может определяться как неформальная институционализация. Отсюда следует, что восприятие коррупции как части повседневной реальности, оправдание коррупционных действий и терпимое к ним отношение становятся наиболее опасными признаками неформальной легитимации и институционализации данного феномена. Истоками этой идеи являются разработки П. Бергера и Т. Лукмана, согласно которым институционализация происходит в ходе взаимной типизации регулярно повторяемых действий (Бергер, Лукман, 1995). По мнению авторов, формирование социального института основано на легитимации институционального мира, которая предполагает способы его «объяснения» и оправдания: «Легитимация “объясняет” институциональный порядок, придавая когнитивную обоснованность объективированным значениям. Легитимация оправдывает институциональный порядок, придавая нормативный характер ею практическим императивам. Важно понять, что легитимация имеет когнитивный и нормативный аспекты. Иначе говоря, легитимация - это не просто вопрос “ценностей”. Она всегда включает также и “знание”» (там же: 153). Здесь затрагиваются ментальные основы конструирования социальной реальности, на что в дальнейшем обратим особое внимание.

Надо заметить, что два обозначенных подхода к изучению коррупции касаются деятельностного аспекта, который позволяет охарактеризовать особенности возникновения коррупционных действий и условия их воспроизводства. Но практика исследования реальных коррупционных взаимодействий редко выходит за рамки теоретизирования, так как перспективы теоретической интерпретации гораздо шире, чем границы эмпирического анализа. Выявление особенностей личного и профессионального опыта реальных участников коррупционных отношений, осуществляемых ими коррупционных действий, специфики условий их социализации и социокультурного про- 
странства общества - эти задачи доступны для теоретического осмысления, но труднодостижимы на эмпирическом уровне. В то же время иные теоретико-методологические перспективы открывает третье направление изучения коррупции.

3. Коррупџия как соџуиальный кониеет. В своей работе «Аутсайдеры: исследования по социологии девиантности» Г. Беккер пишет: «...изучение девиантности является по сути изучением процесса конструирования и подтверждения моральных смыслов в повседневной социальной жизни» (Беккер, 2018: 205). Этим высказыванием исследователь подводит к заключению о том, что девиантность конструируется, так как представляет коллективное действие, которое состоит не только из самих проступков, но и из процесса определения данных проступков в контексте формальной, либо «более или менее неформальной» процедуры (там же: 207). Т. е. в конструировании девиантности участвуют как те лица, которые совершают девиантные поступки, так и те, кто принуждает к соблюдению правовых и моральных норм, применяя в случае нарушения санкции. Здесь проявляются отголоски дюркгеймовских идей о связи преступления и определяемых обществом наказаний. Беккер в свою очередь одновременно артикулирует систему противоправных действий и реакцию окружающих на данные действия, что позволяет идентифицировать поведение как девиантное. Рассуждая таким образом, ученый выдвигает на первый план «всех людей, вовлеченных в какой-либо эпизод предположительной девиантности» (там же: 204).

Проблема в том, что сами действующие лица не всегда имеют конкретные и четкие представления о том, что следует считать девиантным, а что нет. По выражению Беккера, существует некая «драма моральной риторики и действий, в ходе которой выдвигаются, признаются, отвергаются и становятся предметом борьбы обвинения в девиантности» (там же: 208).

Нельзя не отметить, что особенно трудно достичь консенсуса в определении девиантности коррупции. Свой конкретный смысл коррупционные правонарушения получают в законодательном пространстве, хотя и здесь существуют определенные сложности однозначной правовой трактовки, что составляет предмет анализа юридических наук. В нашем случае привлекают внимание размытость единого понимания феномена коррупции в повседневных коммуникациях. Благодарность, подарок, взятка - вот тот неоднородный диапазон определений, который варьируется от ненаказуемых до санкционируемых законом действий, но которыми в разных контекстах могут обозначаться одни и те же жизненные случаи.

Исследуя многозначность понимания и определения коррупции, западные ученые показывают особые преимущества постпозитивистского подхода 


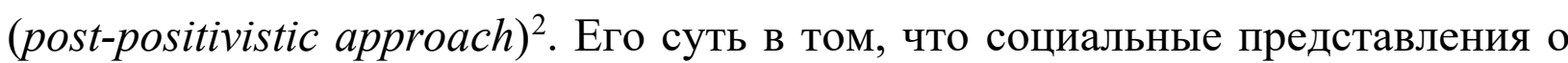
коррупции следует рассматривать в контексте многообразных социальных реальностей (Graaf, Wagenaar, Hoenderboom, 2010). Данное положение содержит ссылки на социальный конструктивизм, где утверждается, что «коррупция - это то, что считается коррупционным в определенном месте и в определенное время» (ibid: 99; здесь и далее перевод наш. - А. П.). В этом же аспекте раскрывается идея о том, что размытость определения феномена коррупции и разрозненность его оценочных коннотаций следует изучать в разных обществах в их уникальном социально-историческом контексте, где конструируется особая социальная реальность (ibid: 102).

Следуя данной логике анализа, мы предлагаем использовать термин «концепт» в рамках разработанного Вал. А. и Вл. А. Луковыми тезаурусного подхода для исследования коррупции как особого социального концепта. В тезаурусе концепт представляет сращение смысла и ценностного отношения, артикулируя сущностные характеристика предмета и его значимость для субъекта. Это некое соединение понятия, чувственного восприятия и внутреннего образа (Луков, В., Луков, Вл., 2008: 111-113). Этот подход позволит в какой-то мере отмежеваться от необходимости поиска однозначной интерпретации коррупции в научных определениях. На уровне концептов многозначность привычного и, казалось бы, понятного для обывателя термина «коррупция» раскрывается в новом контексте, где учитываются субъективные аспекты формируемого знания о том, что такое коррупция.

Итак, если концепт коррупции, распространенный в общественном дискурсе, социально и исторически сконструирован, то стоит обратить внимание на основы определения тех или иных действий именно как коррупционных. С одной стороны, их определяет власть. С другой стороны, концепт коррупции получает свое смысловое наполнение в повседневном понимании. Опять же вернемся к проблеме неопределенности и противоречивости трактовок термина «коррупция» на бытовом уровне. Как обыватель определит материальное поощрение врачу за оказанную услугу? Благодарность это или взятка? И здесь проявляется определенный парадокс понимания коррупции, который состоит в том, что люди, придерживающиеся строгих моральных принципов, в некоторых случаях могут оправдывать коррупционные взаимодействия. Как констатирует А. Папакостас, «чтение нотаций о морали или высоких этических нормах — бесполезное средство для решения этой проблемы» (Папакостас, 2016: 134). Следовательно, в рамках этики данный парадокс разрешить будет сложно.

\footnotetext{
2 Авторы уточняют, что данный подход также может носить следующие названия: культурный (cultural), антропологический (anthropological), неоклассический (neo-classical), постмодерн (post-modern).
} 
Однако западные антропологи Б. Ротштейн и Д. Торселло предлагают взглянуть на данную проблему с другой стороны (Rothstein, Torsello, 2013). Они указывают на унификацию значения коррупции в разных странах, которая везде воспринимается как негативное явление с точки зрения морали (ibid: 22). Но ученые обнаруживают достаточно интересную особенность: восприятие и понимание коррупции обычными людьми зависят не от морально-оценочного фона, а от специфики определения и разграничения общественных и частных благ. В этот процесс также включается ориентация на других людей, поведение которых при столкновении с коррупцией может быть освоено как норма. Но ключевым моментом в определении девиантности коррупционных случаев, становится именно нарушение принципа распределения общественных благ, присваивание которых в любой культуре оценивается как коррупция (ibid: 7). Поэтому, согласно замыслу авторов, коррупцию необходимо рассматривать в контексте ограниченного доступа к общественным благам и их нелегального использования в личных целях (ibid: 8 ).

Таким образом, есть основания полагать, что понимание сущности коррупции на уровне бытового сознания во многом зависит от того, что принято относить к общественным, а что к частным благам в условиях современного общества. Но даже если определить особенности понимания общественных и частных благ (данный срез можно расширить и рассмотреть восприятие коррупции в спектре общественных и частных интересов), связать их с определением коррупционных практик (допустим, оценка индивидом доступных ему должностных ресурсов как частных благ может повлиять на то, какие практики он относит к коррупционным и т. д.), «сформировать» новый концепт коррупции будет крайне сложно. Ведь знания о том, что такое коррупция индивид приобретает в процессе социализации. Точнее, как утверждают ранее упоминавшиеся ученые П. Бергер и Т. Лукман, социальный запас знания, объективированный в том или ином обществе, осваивается в результате интернализации, как основы общего понимания окружающих людей и мира: «Такое понимание возникает не вследствие самостоятельной работы отдельных индивидов по созданию значений, а в результате “перенимания-от-другого: того мира, в котором другие уже живут» (Бергер, Лукман, 1995: 212-213). Суть в том, что в ходе социализации индивид может освоить такие представления, в которых некоторые коррупционные практики (в частности, касающихся решения бытовых вопросов, когда индивид полагает, что не наносит вред обществу) будут считаться нормой, поэтому восприниматься как часть повседневной реальности, как «данность». Это вдвойне усиливает интерес к тому, какие представления о коррупции распространены в совре- 
менных российских семьях, которые интернализируются молодым поколением и становятся частью их миропонимания.

\section{ЗАКЛЮЧЕНИЕ}

Изначально было обращено внимание на то, что коррупция представляет особый социальный феномен, который необходимо осмыслить в русле социологических теорий. Следует переосмыслить те его стороны, изучение которых востребовано курсом антикоррупционной политики. В соответствии с этим была осуществлена попытка охарактеризовать коррупцию как девиантное поведение, социальные практики и социальный концепт. Каждый из этих подходов отнюдь не взаимоисключает и затемняет смысл другого, а наоборот, скорее, взаимодополняет некоторыми элементами своих теорий близкие социологические воззрения.

В обобщенном виде рассмотренные теоретические подходы показывают, что существует значимая связь между условиями социальной жизни и воспроизводством коррупционных действий. Так, представляя коррупцию как определенную разновидность социальных практик, мы артикулируем порождающее начало в диспозициях и условия их формирования. В то же время, признавая преступный характер коррупционных действий, мы подчеркиваем ментальные аспекты конструирования девиантности коррупции в условиях того или иного социума.

Как перейти от теоретических выводов к практико-ориентированным, следует обсуждать отдельно, возможно, этот вопрос потребует освещения в специальной публикации. Но уже сейчас намечается определенный задел в этой области. Так, потребуются исследования восприятия коррупции населением в срезе разграничения общественной и частной сферы. Тогда придет понимание и того, в каком виде феномен коррупции встраивается в картину повседневного мировосприятия. В этом смысле необходимо учитывать, что определение девиантности в общественном дискурсе может не совпадать с правовой интерпретацией. Здесь следует воздействовать через образование и, что примечательно, воспитание, которое оказывает особое влияние на личностное развитие. Добиться существенных результатов будет сложно, так как потребуются усилия не только государства по поддержанию социокультурных условий, препятствующих коррупции, но и самого общества, ориентированного на формирование ответственной позиции и правового сознания. Но двигаться в этом направлении следует, во многом используя потенциал социально-гуманитарного знания. 


\section{СПИСОК ЛИТЕРАТУРЫ}

Беккер, Г. (2018) Аутсайдеры: исследования по социологии девиантности. М. : Элементарные формы. 272 с.

Бергер, П., Лукман, Т. (1995) Социальное конструирование реальности. Трактат по социологии знания. М. : Медиум. 323 с.

Бурдье, П. (2001) Практический смысл. СПб. : Алетейя ; М. : Ин-т эксперимент. социологии. 562 с.

Дюркгейм, Э. (1996) О разделении общественного труда. М. : Канон. $432 \mathrm{c.}$

Дюркгейм, Э. (2006) Социология. Ее предмет, метод, предназначение. М. : «Канон+» РООИ «Реабилитация». 352 с.

Дюркгейм, Э. (2018) Самоубийство. М. : АСТ. 448 с.

Заурвайн, К.-Х. (2012) Коррупция - возвращение «старого» мира в эпоху модерна // Социологическое обозрение. Т. 11. № 3. С. 105-119.

Карепова, С. Г., Некрасов, С. В., Пинчук, А. Н. (2018) К интерпретации понятия «коррупция»: социетальные и социально-психологические аспекты [Электронный ресурс] // Горизонты гуманитарного знания. № 2. С. 52-64. URL: http://journals.mosgu.ru/ggz/article/view/755 (дата обращения: 10.03. 2019). DOI: $\underline{10.17805 / g g z .2018 .2 .5}$

Коркюф, Ф. (2002) Новые социологии. СПб. : Алетейя. 172 с.

Луков, В. А. (2006) Социальное проектирование. М. : Изд-во Моск. гуманит. ун-та; Флинта. 240 с.

Луков, В. А., Луков, Вл. А. (2008) Тезаурусы: Субъектная организация гуманитарного знания. М. : Изд-во Нац. ин-та бизнеса. 784 с.

Мертон, Р. (2006) Социальная теория и социальная структура. М. : АСТ ; АСТ Москва ; Хранитель. 873 с.

Папакостас, А. (2016) Становление цивилизационной публичной сферы: недоверие, доверие и коррупция / пер. с англ. Д. Жихаревича. М. : ВЦИOM. 224 c.

Указ Президента РФ от 29 июня 2018 г. № 378 «О Национальном плане противодействия коррупции на 2018-2020 годы» (2018) [Электронный ресурс] // Информационно-правовой портал «ГАРАНТ». 3 июля. URL: https:// garant.ru/products/ipo/prime/doc/71877694/ [архивировано в WaybackMachine] (дата обращения: 10.03.2019).

Указ Президента РФ от 31 декабря 2015 г. № 683 «О Стратегии национальной безопасности Российской Федерации» (2015) [Электронный ресурс] // Информационно-правовой портал «ГАРАНТ». URL: https://base.garant.ru/ 71296054/ [архивировано в WaybackMachine] (дата обращения: 10.03.2019).

Alatas, S. H. (1968) The sociology of corruption: The nature, function, causes and prevention of corruption. Singapore : Donald Moore Press Ltd. 87 p. 
Graaf, G. de (2007) Causes of corruption: Towards a contextual theory of corruption // Public Administration Quarterly. Vol. 31. No. 1. P. 39-86.

Graaf, G. de, Wagenaar, P., Hoenderboom, M. (2010) Constructing corruption // The good cause: Theoretical perspectives on corruption / ed. by G. de Graaf, P. von Maravic, P. Wagener. Opladen ; Farmington Hills : Barbara Budrich Publishers. 204 p. P. $98-114$.

Osipov, G. et al. (2018) Corruption potential as a special phenomenon: Theoretical and methodological analysis / G. Osipov, S. Karepova, A. Pinchuk, S. Nekrassov // Proceedings of the 32nd International Business Information Management Association Conference - Vision 2020: Sustainable economic development and application of innovation management from regional expansion to global growth. November 15-16, 2018, Seville, Spain. Seville. P. 1257-1266.

Rothstein, B., Torsello, D. (2013) Is corruption understood differently in different culture? Anthropology meets political science [Электронный pecypc] // QoG Working Paper Series. No. 5. P. 1-27. URL: https://www.qog.pol.gu. se/digitalAssets/1443/1443545 2013 5 rothstein torsello.pdf [архивировано в WaybackMachine] (дата обращения: 10.03.2019).

Wacquant, L. (1992) Toward a social praxeology: The structure and Logic of Bourdieu's sociology // Bourdieu P., Wacquant L. An invitation to reflexive sociology. Chicago : The University of Chicago Press. xiv, 332 p. P. 1-59.

Дата поступления: 11.03.2019 2.

\section{REFERENCES}

Becker, H. S. (2018) Autsaidery: issledovaniia po sotsiologii deviantnosti [Outsiders: Studies in the sociology of deviance]. Moscow : Elementarnye formy Publ. 272 p. (In Russ.).

Berger, P. L. and Luckmann, T. (1995) Sotsial'noe konstruirovanie real'nosti. Traktat po sotsiologii znaniia [The social construction of reality. A treatise on sociology of knowledge]. Moscow : Medium Publ. 323 p. (In Russ.).

Bourdieu, P. (2001) Prakticheskii smysl [Practical reason]. St. Petersburg : Aleteiia Publ. ; Moscow : Institute of Experimental Sociology Publ. 562 p. (In Russ.).

Durkheim, É. (1996) O razdelenii obshchestvennogo truda [The division of labour in society]. Moscow : Kanon Publ. 432 p. (In Russ.).

Durkheim, É. (2006) Sotsiologiia. Ee predmet, metod, prednaznachenie [Sociology and its scientific domain]. Moscow : Kanon+ Publ., RPOD "Reabilitatsiia”. 352 p. (In Russ.).

Durkheim, É. (2018) Samoubiistvo [Suicide]. Moscow : AST Publ. 448 p. (In Russ.). 
Saurwein, K.-H. (2012) Korruptsiia — vozvrashchenie «starogo» mira v epokhu moderna [Corruption - a return of the "old world" in modern age?]. Sotsiologicheskoe obozrenie, vol. 11, no. 3, pp. 105-119. (In Russ.).

Karepova, S. G., Nekrasov, S. V. and Pinchuk, A. N. (2018) K interpretatsii poniatiia «korruptsiia»: sotsietal'nye i sotsial'no-psikhologicheskie aspekty [On the interpretation of the concept "Corruption": Societal and socio-psychological aspects]. Gorizonty gumanitarnogo znaniia, no. 2, pp. 52-64. [online] Available at: http://journals.mosgu.ru/ggz/article/view/755 (accessed 10.03.2019). DOI: 10.17 805/ggz.2018.2.5

Corcuff, P. (2002) Novye sotsiologii [New sociologies]. St. Petersburg : Aleteiia Publ. 172 p. (In Russ.).

Lukov, V. A. (2006) Sotsial'noe proektirovanie [Social projection]. Moscow : Moscow University for the Humanities Publ. ; Flinta Publ. 240 p. (In Russ.).

Lukov, V. A. and Lukov, Vl. A. (2008) Tezaurusy: Sub"ektnaia organizatsiia gumanitarnogo znaniia [Thesauri: The subjective organization of humanities knowledge]. Moscow : Moscow University for the Humanities Publ. 784 p. (In Russ.).

Merton, R. (2006) Sotsial'naia teoriia i sotsial'naia struktura [Social theory and social structure]. Moscow : AST Publ. ; AST Moskva Publ. ; Khranitel' Publ. 873 p. (In Russ.).

Papakostas, A. (2016) Stanovlenie tsivilizatsionnoi publichnoi sfery: nedoverie, doverie i korruptsiia [Civilizing the public sphere: Distrust, trust and corruption] / transl. from English by D. Zhikharevich. Moscow : Russian Public Opinion Research Center (VTsIOM). 224 p. (In Russ.).

Ukaz Prezidenta RF ot 29 iiunia 2018 g. № 378 «O Natsional'nom plane protivodeistviia korruptsii na 2018-2020 gody» [Executive order of the President of Russia of June 29, 2018, no. 378 "National Anti-corruption Plan for 20182020"]. (2018) Informatsionno-pravovoi portal "GARANT", July 3. [online] Available at: https://garant.ru/products/ipo/prime/doc/71877694/ [archived in WaybackMachine] (accessed 10.03.2019). (In Russ.).

Ukaz Prezidenta RF ot 31 dekabria 2015 g. № 683 «O Strategii natsional'noi bezopasnosti Rossiiskoi Federatsii» [Executive order of the President of Russia of December, 2015, no. 683 "Strategy of National Security of the Russian Federation"]. (2015) Informatsionno-pravovoi portal "GARANT" [online] Available at: https://base.garant.ru/71296054/ [archived in WaybackMachine] (accessed 10.03. 2019). (In Russ.).

Alatas, S. H. (1968) The sociology of corruption: The nature, function, causes and prevention of corruption. Singapore : Donald Moore Press Ltd. 87 p.

Graaf, G. de (2007) Causes of corruption: Towards a contextual theory of corruption. Public Administration Quarterly, vol. 31, no. 1, pp. 39-86. 
Graaf, G. de, Wagenaar, P. and Hoenderboom, M. (2010) Constructing corruption. In: The good cause: Theoretical perspectives on corruption / ed. by G. de Graaf, P. von Maravic and P. Wagener. Opladen ; Farmington Hills : Barbara Budrich Publishers. 204 p. Pp. 98-114.

Osipov, G. et al. (2018) Corruption potential as a special phenomenon: Theoretical and methodological analysis / G. Osipov, S. Karepova, A. Pinchuk and S. Nekrassov. In: Proceedings of the 32nd International Business Information Management Association Conference - Vision 2020: Sustainable economic development and application of innovation management from regional expansion to global growth. November 15-16, 2018, Seville, Spain. Seville. Pp. 1257-1266.

Rothstein, B., Torsello, D. (2013) Is corruption understood differently in different culture? Anthropology meets political science. QoG Working Paper Series, no. 5, pp. 1-27. [online] Available at: https://www.qog.pol.gu.se/digitalAssets/ 1443/1443545 2013 5 rothstein torsello.pdf [archived in WaybackMachine] (accessed 10.03.2019).

Wacquant, L. (1992) Toward a social praxeology: The structure and Logic of Bourdieu's sociology. In: Bourdieu P. and Wacquant L. An invitation to reflexive sociology. Chicago : The University of Chicago Press. xiv, 332 p. Pp. 1-59.

Submission date: 11.03.2019.

Пинчук Антонина Николаевна - кандидат социологических наук, научный сотрудник Института социально-политических исследований Российской академии наук. Адрес: 119333, г. Москва, ул. Фотиевой, д. 6, корп. 1. Тел.: +7 (499) 530-28-84. Эл. адрес: antonina.pinchuk27@,bk.ru

Pinchuk Antonina Nikolaevna, Candidate of Sociology, Research Associate, Institute of Socio-Political Research, Russian Academy of Sciences. Postal address: Bldg. 1, 6 Fotievoi St., 119333 Moscow, Russian Federation. Tel.: +7 (499) 530-28-84. E-mail: antonina.pinchuk27@bk.ru

Для цитирования:

Пинчук А. Н. Коррупция в свете социологических теорий [Электронный pecypc] // Горизонты гуманитарного знания. 2019. № 2. C. 80-95. URL: http://journals.mosgu.ru/ggz/article/view/1006 (дата обращения: дд.мм.гггг). DOI: $10.17805 /$ ggz.2019.2.6 